\title{
An audit of traumatic brain injury (TBI) in a busy developing-world trauma service exposes a significant deficit in resources available to manage severe TBI
}

\author{
E Jerome, ${ }^{1} \mathrm{MB}$ ChB, MRCS (Edin); G L Laing, ${ }^{1}$ FCS (SA), Cert Trauma Care, PhD; J L Bruce, ${ }^{1}$ FCS (SA); \\ B Sartorius, ${ }^{2}$ BSc, BSc Hons, MSc, PhD; P Brysiewicz, ${ }^{3}$ BSocSc, BA, MCur, PhD; D L Clarke, ${ }^{1,4}$ FCS (SA), MMedSci, MBA, MPhil, PhD \\ ${ }^{1}$ Department of Surgery, Pietermaritzburg Metropolitan Trauma Service, University of KwaZulu-Natal, Pietermaritzburg, South Africa \\ ${ }^{2}$ Discipline of Public Health Medicine, School of Nursing and Public Health, University of KwaZulu-Natal, Durban, South Africa \\ ${ }^{3}$ Discipline of Nursing, School of Nursing and Public Health, University of KwaZulu-Natal, Durban, South Africa \\ ${ }^{4}$ Department of Surgery, Faculty of Health Sciences, University of the Witwatersrand, Johannesburg, South Africa
}

Corresponding author: P Brysiewicz (brysiewiczp@ukzn.ac.za)

\begin{abstract}
Background. Traumatic brain injury (TBI) affects large numbers of patients, both adults and children, and significant resources are needed to manage it.

Objective. To determine the burden of TBI and the adequacy of available resources to manage in the Pietermaritzburg Metropolitan Trauma Service (PMTS).

Methods. All patients with a TBI were identified from the hybrid electronic medical registry at Grey's and Edendale hospitals in Pietermaritzburg (PMB), KwaZulu-Natal, South Africa. Patients were classified according to severity of head injury and age. We defined mild TBI as Glasgow coma scale (GCS) 13 - 15, moderate as GCS 9 - 12, and severe as GCS $\leq 8$, in accordance with international standards. We divided the cohort according to ages 0 - 5 years, $6-10$ years, $>10-17$ years and adults ( $>17$ years).

Results. From January 2012 to December 2014, 3301 patients were treated for TBI in PMB. The mean age was 27.4 (standard deviation 14.4) years. There were 2632 males and 564 females. There were 2540 mild, 326 moderate, and 329 severe TBI admissions during the period under review. A total of 139 (4.2\%) patients died. A total of $242(7.3 \%)$ patients were admitted to the intensive care unit (ICU), of whom $137(57.0 \%)$ had a GCS of $\leq 9$. Only $27.0 \%$ of patients with a GCS of $\leq 9$ were admitted to the ICU.

Conclusion. There is a significant burden of TBI managed by the PMTS. Critical care resources available to manage patients with TBI are inadequate.
\end{abstract}

S Afr Med J 2017;107(7):621-625. DOI:10.7196/SAMJ.2017.v107i7.10562

Trauma is a leading cause of death in children and young adults in South Africa (SA), where the rate of mortality from motor vehicle collisions and interpersonal violence is respectively five and four times the global average. ${ }^{[1,2]}$ In sub-Saharan Africa the incidence of traumatic brain injury (TBI) is $150-170 / 100000$ compared with a global average of $106 / 100000 \cdot \cdot^{[1-7]}$ The vast majority of patients are admitted with mild TBI (Glasgow coma scale (GCS) 13 - 15); these injuries are usually self-limiting and do not require significant resources. However, there is consensus that severe TBI, as defined by a GCS $\leq 8$, should be managed according to well-defined protocols that include mechanical ventilation, intracranial pressure (ICP) monitoring to facilitate pharmacological and/or surgical control, and aggressive imaging to identify patients who require a neurosurgical operation. ${ }^{[7-11]}$ Over the past 25 years several institutions have produced algorithms and guidelines to provide direction to clinicians managing TBI. In 1996, the Brain Trauma Foundation (BTF) published the first of such guidelines on the management of severe TBI, which were accepted by the American Association of Neurological Surgeons and the World Health Organization Committee in Neurotraumatology. ${ }^{[7]}$ Four years later, at the beginning of the millennium, a revised edition was published; these guidelines have been updated at regular intervals, i.e. in 2003 and 2007. Over the same period, a burgeoning body of literature has emerged, which supports the enforcement of guideline-based management protocols for severe TBI. This literature has empha- sised that in severe TBI, maintaining intracerebral homeostasis by regulating physiological parameters, such as blood pressure, oxygenation, arterial carbon dioxide, and cerebral perfusion pressure, prevents secondary brain injury and improves outcomes. In lowand middle-income countries there is a general lack of resources to manage these problems. ${ }^{[7-11]}$ In Africa there is an average of one neurosurgeon per 10000000 population, in contrast to the situation in the developed world, where there are 102 neurosurgeons per 10000000 population in Europe and 56 per 10000000 population globally. ${ }^{[12-14]}$ The development of an electronic surgical registry at our institution has allowed us to capture data in real-time of all surgical patients, to provide a detailed overview of the burden of TBI in our service, and to provide an accurate needs assessment of the resources necessary to manage severe TBI according to international standards. ${ }^{[15]}$

\section{Setting}

The Pietermaritzburg Metropolitan Trauma Service (PMTS) provides tertiary trauma care for 3 million people in Pietermaritzburg (PMB) and western KwaZulu-Natal, SA. Two sites - Grey's Hospital and Edendale Hospital - yearly admit 2 500 - 3000 trauma patients. There are 12 intensive care unit (ICU) beds and 6 highcare beds for adults, and 12 paediatric ICU beds, which are shared with medicine and other surgical specialties. There is no specialist neurosurgical service in the state sector in PMB. All patients with 
TBI are managed by the emergency department and surgical teams. Once the patient has been resuscitated and imaging scans have been obtained, these are discussed with staff at the neurosurgical service in Durban. During the neurosurgical consultation a decision is made with regard to the definitive management plan for the patient. Patients accepted by the neurosurgical service are either transported by road or airlifted to Durban, as appropriate. The PMTS maintains a prospective digital trauma registry, which captures data at our institutions. The admitting doctor clerks the patient onto an electronic pro-forma. This is the clerking process for all new trauma admissions - the clinical data are therefore entered in real-time. As the data are entered, these are directly incorporated into the registry. The completed pro forma is then printed out and becomes the patient's clinical record. At operation and at discharge or death a similar process is followed. This system combines the functions of a medical registry and medical record system. It also combines an electronic system with a paper-based system - the hybrid electronic medical registry.

\section{Methods}

All patients with a TBI were identified from the hybrid electronic medical registry at Grey's and Edendale hospitals in PMB from January 2012 to December 2014. Standard demographic data were analysed. Patients were classified according to severity of head injury and age. We defined a severe TBI as GCS $\leq 8$, moderate as GCS 9 - 12 and mild as GCS $13-15$, in line with international standards. We divided the cohort according to ages $0-5$ years, $6-10$ years, $>10-17$ years and adults ( $>17$ years). We reviewed the patients who were admitted to the ICU and then used the BTF guidelines ${ }^{[7]}$ for the management of severe TBI to establish how many patients who met the criteria for admission to an ICU were not admitted. This difference is a so-called gap analysis. Data were processed and analysed using Stata version 13.0 (StataCorp., USA) ${ }^{[16]}$ Differences in frequencies of categorical outcomes by GCS category were assessed using Pearson's $\chi^{2}$ test or Fisher's exact test if any expected cell count was $<5$ observations. Differences in mean GCS of classification or outcome (e.g. mortality) were assessed using Student's $t$-test.

Ethics approval to maintain the registry has been obtained from the Biomedical Research Ethics Committee (ref. no. BCA221/13 BREC) of the University of KwaZulu-Natal, Durban, SA, and from the Research Unit of the Department of Health.

\section{Results}

During January 2012 - December 2014, a total of 3301 patients were treated for TBI in PMB; the data had various levels of completeness across the variables. The mean age of the patients was 27.4 (standard deviation (SD) 14.4) (range 0 - 92) years. There were 2632 males and 564 females, with a male to female ratio of 4.7:1. The breakdown by ethnicity (Fig. 1) was overwhelmingly black African (96\%), followed by Asian (2\%), white (1\%) and mixed race (1\%) patients. The mechanism of TBI (Fig. 2) was primarily interpersonal violence (39.4\%), followed by motor vehicle collision (16.7\%), and pedestrian-vehicle collision (14.1\%). The breakdown of the admission GCS is provided in Table 1 and Fig. 3. There were 2540 mild, 326 moderate, and 329 severe TBI cases during the period reviewed. A total of 139 (4.2\%) patients died, and 242 (7.3\%) were admitted to the ICU. ICU admission by GCS category varied significantly (Table 1). Only 33.4\% (110/329) of patients with a GCS $\leq 8$ were admitted to the ICU. The mean GCS (SD) among those who survived was 13.7 (2.6) compared with 5.7 (4.0) among those who died $(p<0.001)$. Fig. 4 highlights the difference in the distribution of GCS score by mortality outcome. Thirty-three percent (110/329)

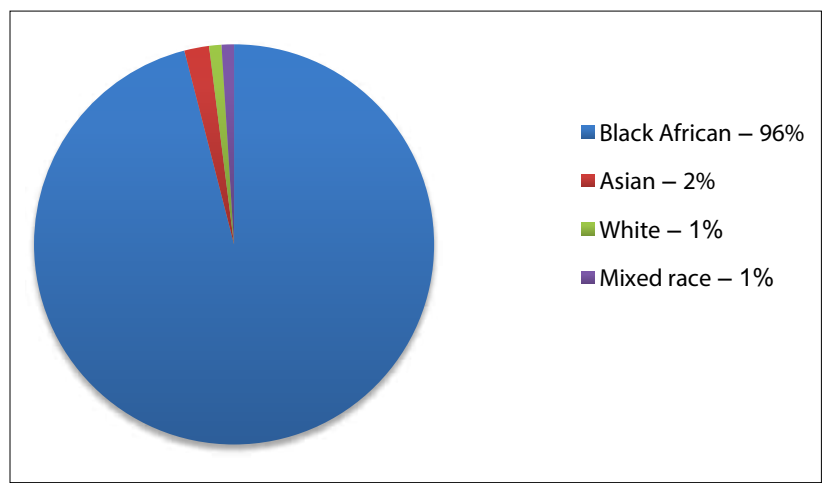

Fig. 1. Breakdown, according to ethnicity, of patients admitted with traumatic brain injury.

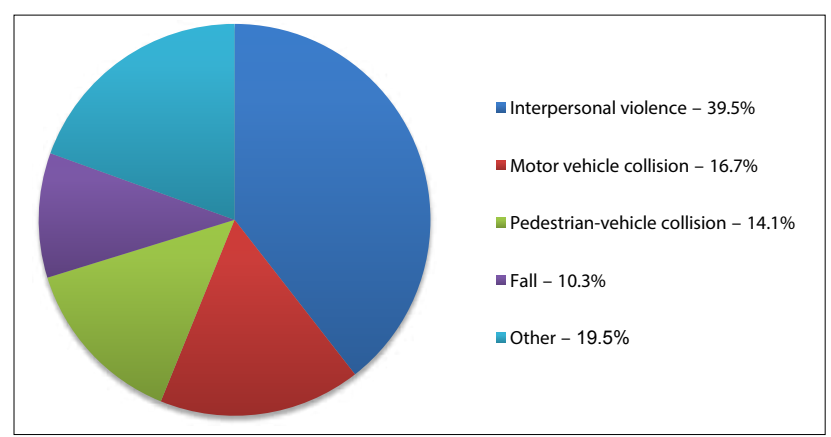

Fig. 2. Mechanism of traumatic brain injury.

of patients with an admission GCS $\leq 8$ died, whereas only $4.0 \%$ $(13 / 326)$ and $0.6 \%(16 / 2540)$ of those with an admission GCS of $9-12$ and $\geq 13$, respectively, died $(p<0.001)$. A total of $69(2.5 \%)$ patients had a saturation reading of $<90$ on presentation. Fig. 5 shows the incidence of hypoxia compared with the GCS. Of these patients with hypoxia, 22 (31.0\%) were admitted to the ICU. Of the patients who were not hypoxic, 5.6\% were admitted to the ICU. Fig. 6 shows the rate of ICU admission compared with the GCS. A total of 2383 computed tomography (CT) scans were performed; 1789 (75\%) demonstrated intracranial pathology.

Patients considered for palliation on initial assessment owing to the presence of clinical signs indicative of irreversible injury, such as Cushing's reflex or fixed and dilated pupils, represented 19.1\% of severe TBI admissions (63/329); of these, 79.4\% (50/63) died during their admission. These patients did not undergo a CT scan. Of the survivors, 11/13 were discharged to their base hospital for palliation and were not expected to improve or leave hospital. There was a positive finding in $95 \%$ of patients $(252 / 266)$ with severe TBI who underwent CT. Of these, $22.2 \%(56 / 252)$ were accepted by the neurosurgical unit at the tertiary hospital in Durban. Fig. 7 compares the need for surgery against GCS on presentation. The majority $(77.8 \% ; 196 / 252)$ were managed in the general surgical ward. In total, $59.7 \%(117 / 196)$ of patients who had a positive CT scan and who were not accepted into the neurosurgical unit were not admitted to the ICU, and were treated in the general ward. A total of $15.2 \%$ $(12 / 79)$ of severe TBI patients admitted to the ICU died, compared with $38.5 \%(55 / 117)$ of those treated in the ward, while $38.5 \%$ $(62 / 117)$ managed in the ward survived.

\section{Discussion}

The abovementioned data are in keeping with numerous SA reports on trauma, which demonstrate a huge burden of trauma and injury due to interpersonal violence. There can be little doubt that trauma 
Table 1. Summary of study subjects by GCS classification

\begin{tabular}{|c|c|c|c|c|c|c|c|}
\hline $\begin{array}{l}\text { Admission GCS } \\
\text { category }\end{array}$ & Variable & $N$ & $\begin{array}{l}\text { Mean/proportion } \\
\text { (SD) }\end{array}$ & Median & IQR & Minimum & Maximum \\
\hline \multirow[t]{6}{*}{ Mild } & Admission GCS & 2540 & $14.75(0.55)$ & 15 & $15-15$ & 13 & 15 \\
\hline & Age & 2520 & $27.16(14.2)$ & 26 & $19-34$ & 0 & 92 \\
\hline & Died & 2540 & 0.01 & - & - & - & - \\
\hline & ICU & 2530 & 0.03 & - & - & - & - \\
\hline & $\mathrm{O}_{2} \mathrm{SAT}<90$ & 2262 & 0.01 & - & - & - & - \\
\hline & Surgery & 2540 & 0.26 & - & - & - & - \\
\hline \multirow[t]{6}{*}{ Moderate } & Admission GCS & 326 & $10.51(1.10)$ & 10 & $10-11$ & 9 & 12 \\
\hline & Age & 322 & $26.83(14.3)$ & 27 & $19-34$ & 1 & 75 \\
\hline & Died & 326 & 0.04 & - & - & - & - \\
\hline & ICU & 326 & 0.14 & - & - & - & - \\
\hline & $\mathrm{O}_{2}$ SAT $<90$ & 269 & 0.04 & - & - & - & - \\
\hline & Surgery & 326 & 0.31 & - & - & - & - \\
\hline \multirow[t]{6}{*}{ Severe } & Admission GCS & 329 & $5.21(1.98)$ & 6 & $3-7$ & 2 & 8 \\
\hline & Age & 328 & $30.16(15.49$ & 28 & $21-36$ & 0 & 87 \\
\hline & Died & 329 & 0.33 & - & - & - & - \\
\hline & ICU & 329 & 0.33 & - & - & - & - \\
\hline & $\mathrm{O}_{2} \mathrm{SAT}<90$ & 175 & 0.18 & - & - & - & - \\
\hline & Surgery & 329 & 0.40 & - & - & - & - \\
\hline \multirow[t]{5}{*}{ Not recorded } & Age & 4 & $25.75(4.43)$ & 26 & $22-30$ & 21 & 30 \\
\hline & Died & 106 & 0.00 & - & - & - & - \\
\hline & ICU & 4 & 0.25 & - & - & - & - \\
\hline & $\mathrm{O}_{2} \mathrm{SAT}<90$ & 0 & - & - & - & - & - \\
\hline & Surgery & 106 & $0.98(0.14)$ & 1 & $1-1$ & 0 & 1 \\
\hline \multirow[t]{6}{*}{ Overall } & Admission GCS & 3195 & $13.33(3.16)$ & 15 & $14-15$ & 2 & 15 \\
\hline & Age & 3174 & $27.43(14.4)$ & 26 & $19-34$ & 0 & 92 \\
\hline & Died & 3301 & 0.04 & - & - & - & - \\
\hline & ICU & 3189 & 0.08 & - & - & - & - \\
\hline & $\mathrm{O}_{2} \mathrm{SAT}<90$ & 2706 & 0.03 & - & - & - & - \\
\hline & Surgery & 3301 & 0.30 & - & - & - & - \\
\hline
\end{tabular}

and injury represent a public health crisis of equal magnitude to infectious diseases and emerging diseases of lifestyle in sub-Saharan Africa. This burden is disproportionately borne by young adults and is further distinguished from the situation in other regions, as just under half $(47 \%)$ of the patients with TBI in this audit sustained an intentional injury. ${ }^{[1-6,12-14]}$ This is in stark contrast to international data, which suggest that $\sim 80 \%$ of all TBI is a result of non-intentional trauma, i.e. motor vehicle collisions (60\%), falls (10\%), and workplace or leisure-related injuries (10\%). A comprehensive public health response to this problem is required, emphasising primary preventive strategies and increased resources for secondary prevention.

Most of the published guidelines suggest that all patients with severe TBI require CT scans and should be managed in an institution, which can undertake both craniotomy and ICP monitoring. ${ }^{[7-11]}$ This target is clearly not being met in our system. The majority $(77.8 \%)$ of severe TBI patients with positive CT scans were managed in the general surgical unit. Of the patients with severe TBI and positive CT scans, who were not accepted by the neurosurgical unit, the majority $(59.7 \%)$ were not admitted to the ICU, but were treated in the general ward. The mortality is higher in patients managed in the general ward (38.5\%) compared with those managed in the ICU (15.2\%). This almost certainly reflects a crude form of triage, where patients deemed to have an extremely poor prognosis are not admitted to the ICU but rather to the general ward - in the expectation that they will have a poor outcome. The danger with this approach is that it risks becoming a self-fulfilling prediction. However, it is also highly probable that the 62 patients with a severe TBI who survived after being managed in a general surgical unit would have benefited from more sophisticated neuroprotective strategies available in the ICU.

This audit has revealed a significant burden of TBI, particularly of severe TBI. The PMTS manages $\sim 2$ patients with a severe head injury every week. Resources available to manage these patients are inadequate, as evidenced by only $41.3 \%$ of patients with a severe TBI being managed in the ICU. Globally, access to acute specialist neurosurgical services is limited. This is especially true in our environment, and the care of TBI remains largely in the hands of generalists. These generalists may need to be up-skilled in a number 


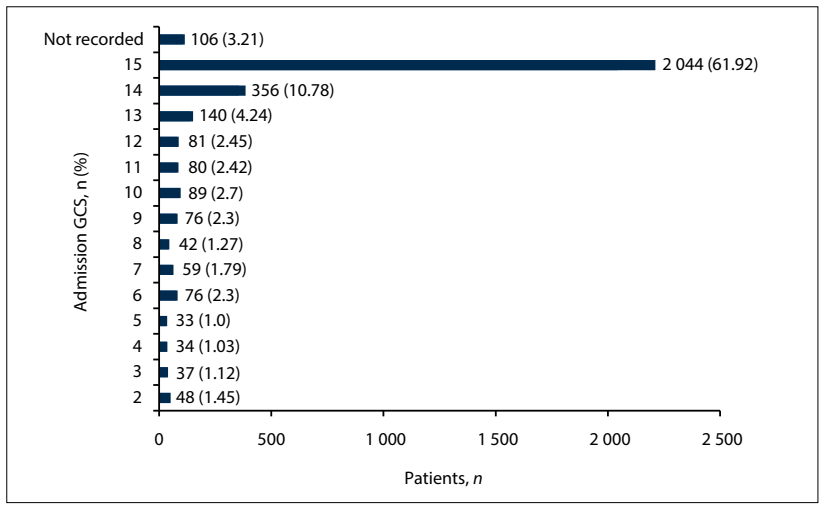

Fig. 3. Breakdown of admissions compared with the Glasgow coma scale (GCS).

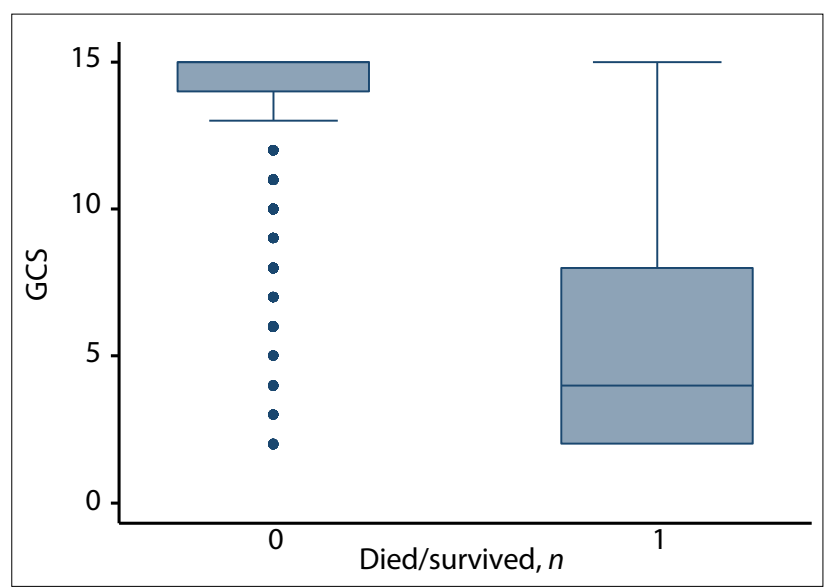

Fig. 4. Mortality v. Glasgow coma scale (GCS) (died - 0, survived - 1).

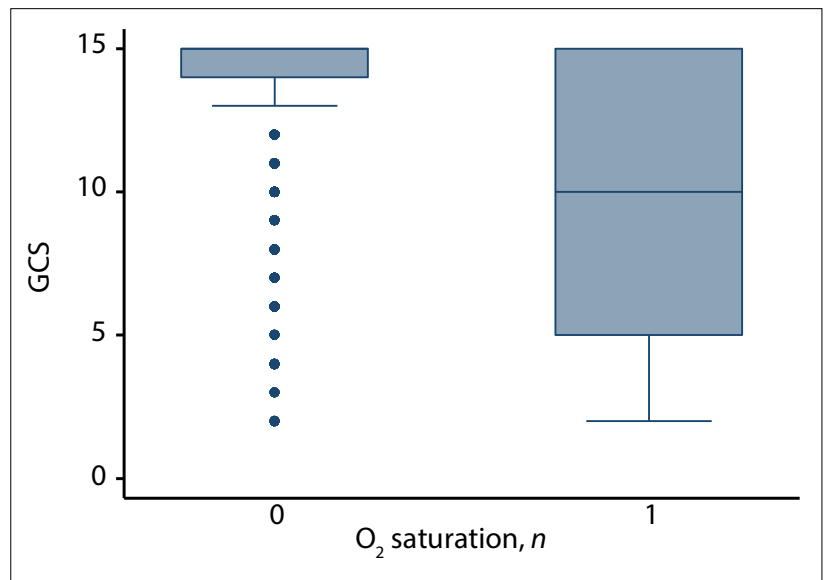

Fig. 5. Hypoxia v. Glasgow coma scale (GCS) (no hypoxia - 0, episode of hypoxia-1).

of tasks and procedures, such as placement of ICP monitors and basic neurosurgical operations. However, there is also a major deficit in the resources available to treat severe TBI patients in our setting, and to improve outcomes will be difficult without an increase in the available resources. Injury-prevention programmes are needed to reduce the incidence of TBI, but increased resources need to be made available to limit the sequelae of TBI.

\section{Conclusion}

PMTS manages a significant burden of TBI. The resources available to manage the problem are inadequate. To address this deficit requires

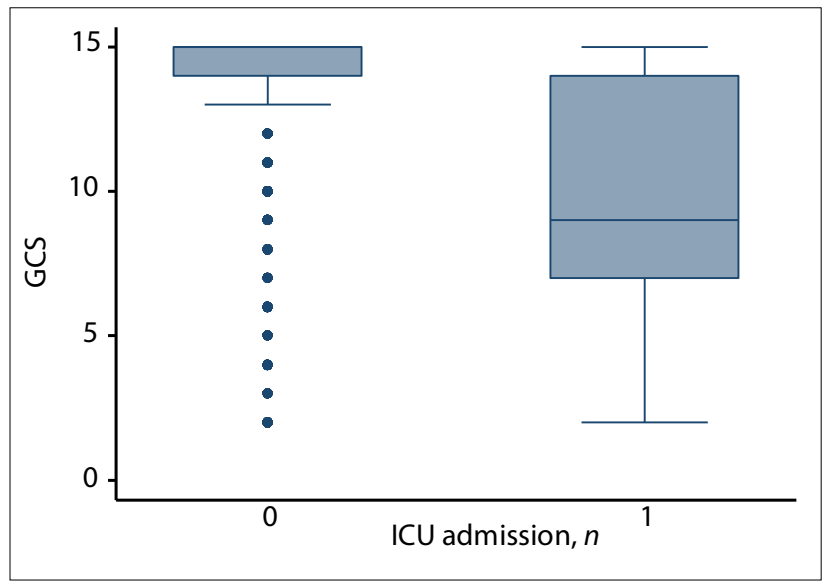

Fig. 6. Intensive care unit admission v. Glasgow coma scale (GCS) (not admitted-0, admitted-1).

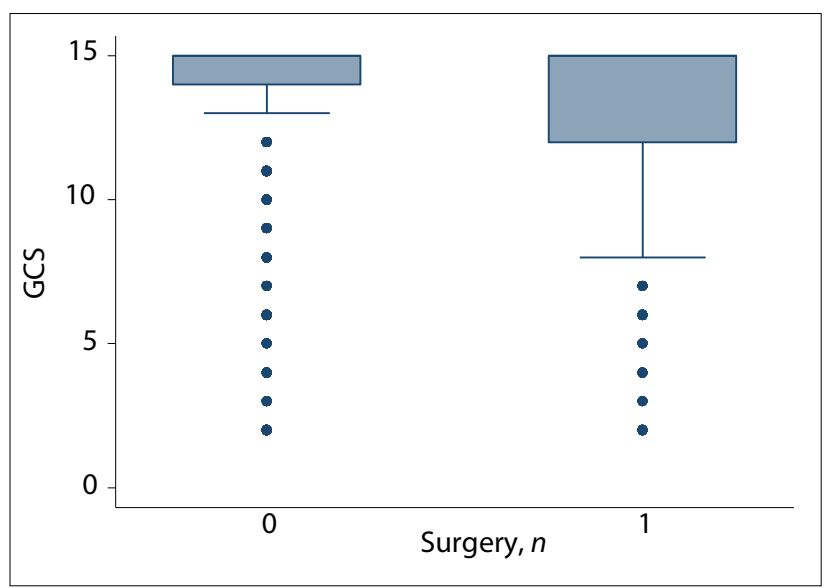

Fig. 7. Need for surgery admission v. Glasgow coma scale (GCS) (no surgery - 0, surgery - 1).

major infrastructural development and increased access to ICU beds, as well as the development of on-site neurosurgical services and ICP monitoring facilities.

\section{Acknowledgements. None}

Author contributions. EJ: data cleaning, analysis and drafting of article; GLL: design of data capture instrument; JLB: database maintenance and data retrieval; BS: statistics; PB: drafting of article, reference checking, coordination of submission; and DLC: senior author, general supervision, co-ordination and assistance at all levels.

\section{Funding. None.}

\section{Conflicts of interest. None.}

1. Parkinson F, Kent SJ, Aldous C, Oosthuizen G, Clarke D. The hospital cost of road traffic accidents at a South African regional trauma centre: A micro-costing study. Injury 2014;45(1):342-345. http://dx.doi. org/10.1016/ji.injury.2013.04

2. Laing GL, Skinner DL, Bruce JL, Aldous C, Oosthuizen GV, Clarke DL. Understanding the burden . Laing GL, Skinner DL, Bruce JL, Aldous C, Oosthuizen GV, Clarke DL. Understanding the burden
and outcome of trauma care drives a new trauma systems model. World J Surg 2014;38(7):1699-1706. and outcome of trauma care drives a new trau

3. Hyder AA, Wunderlich CA, Puvanachandra P, Gururaj G, Kobusingye OC. The impact of traumatic brain injuries: A global perspective. NeuroRehab 2007;22(5):341-353.

4. Wong JC, Linn KA, Shinohara RT, Mateen FJ. Traumatic brain injury in Africa in 2050: A modeling study. Eur J Neurol 2015;23(2):382-386. http://dx.doi.org/10.1111/ene.12877

5. Webster J, Taylor A, Balchin R. Traumatic brain injury, the hidden pandemic: A focused response to family and patient experiences and needs. S Afr Med J 2015;105(3):195-198. http://dx.doi.org/10.7196/ SAMJ.9014

6. Tran TM, Fuller AT, Kiryabwire J, et al. Distribution and characteristics of severe traumatic brain injury at Mulago National Referral Hospital in Uganda. World Neurosurg 2015;83(3):269-277. http:// dx.doi.org/10.1016/j.wneu.2014.12.028 
7. Brain Trauma Foundation. Guidelines for the Management of Severe Traumatic Brain Injury. 3rd ed. Campbell, CA, USA: BTF, 2007. https://http://www.braintrauma.org/pdf/protected/Guidelines_ Management_2007w bookmarks.pdf (accessed 8 May 2017).

8. Cushman JG, Agarwal N, Fabian T, et al. Practice management guidelines for the management of mild traumatic brain injury: The EAST Practice Management Guidelines Work Group. J Trauma 2001;51(5):1016-1026. http://dx.doi.org/10.1097/00005373-200111000-00034

9. Committee on Quality Improvement, American Academy of Pediatrics, Commission on Clinical Policies and Research, American Academy of Family Physicians. The management of minor closed head injury in children. Pediatrics 1999;104(6):1407-1415.

10. Committee on Trauma, American College of Surgeons. Advanced Trauma Life Support for Doctors. Head Trauma. 6th ed. Chicago: ACS, 1997.

11. Ingebrigtsen T, Romner B, Kock-Jensen C. Scandinavian guidelines for initial management of minimal, mild and moderate head injuries. J Trauma 2000:48(4):760-766. http://dx.doi.org/10.1097/00005373200004000-00029

12. Nell V, Brown D. Epidemiology of traumatic brain injury in Johannesburg - II. Morbidity, mortality and etiology. Soc Sci Med 1991;33(3):289-296. http://dx.doi.org/10.1016/0277-9536(91)90363-H
13. Zulu BM, Mulaudzi TV, Madiba TE, Muckart DJ. Outcome of head injuries in general surgical units with an off-site neurosurgical service. Injury 2007;38(5):576-583. http://dx.doi.org/10.1016/j units with an off-

14. Okyere-Dede EK, Nkalakata MC, Nkomo T, Hadley GP, Madiba TE. Paediatric head injuries in the KwaZulu-Natal Province of South Africa: A developing country perspective. Trop Doct 2013;43(1):1-4 http://dx.doi.org/10.1177/0049475513480490

5. Laing GL, Bruce JL, Skinner DL, Allorto NL, Clarke DL, Aldous C. Development, implementation an evaluation of a hybrid electronic medical record system specifically designed for a developing worl surgical service. World J Surg 2014;38(6):1388-1397. http://dx.doi.org/10.1007/s00268-013-2438-2

16. StataCorp. Stata Statistical Software: Release 13. College Station, TX: StataCorp LP, 2013

Accepted 6 March 2017. 